\title{
EL TEMA DE LA AUTONOMIA PROVINCIAL: LAS DIPUTACIONES Y EL PROCESO AUTONOMICO
}

\author{
POR \\ Sebastián Martín-Retortillo Baquer \\ Catedrático de Derecho Administrativo \\ de la Universidad Complutense de Madrid
}

\begin{abstract}
SUMARIO: I. El polémico tema de las Diputaciones provinciales.-ll. La GARANTIA INSTITUCIONAL DE LA PROVINCIA EN LA CE: 1. Las Diputaciones provinciales en el Anteproyecto y en el texto de la CE. 2. Referencia a la doctrina del TC.-III. LA autonomia de las Diputaciones provinciales en el CONTEXTO de la aUtonomía de las CORPORACIONES LoCALES: SU CONCRECIÓN.-IV. El trataMIENTO del TEMA EN LOS ESTATUTOS de Autonomia; Remisión. La provincia en la Ley reguladora de las Bases del RéGIMEN LOCAL.-V. LA COORDINACIÓN DE LAS COMPETENCIAS PROVINCIALES POR LAS CORRESPONDIENteS COMUNidAdes Autónomas: 1. Consideraciones generales. 2. La Ley de Cataluña 5/1987, de 4 de abril, de régimen provisional de las competencias de las Diputaciones provinciales y la alternativa comarcal recogida en la Ley 6/1987, de la misma fecha.-VI. LAS DIPUTACIONES PROVINCIALES COMO ADMINISTRACIÓN PERIFÉRICA DE las Comunidades Autónomas.-VII. Consideraciones finales.
\end{abstract}

\section{EL POLEMICO TEMA DE LAS DIPUTACIONES PROVINCIALES}

Los temas estrictamente organizativos, no obstante lo que aparentemente pueda parecer, presentan en ocasiones una inequívoca carga polémica. Es fácil advertirla. Basta que se penetre en la realidad que con frecuencia subyace en ellos y se consideren las distintas fuerzas que confluyen en sus planteamientos $y$ en las reformas que de los mismos pretenden llevarse a cabo. Realidad que cabe contrastar, insisto, si se superan los análisis puramente formales de estas cuestiones organizativas y se ahonda un poco, tratando de ver que hay realmente detrás de ellas. En ocasiones, son las siempre problemáticas cuestiones competenciales referentes a las que puedan corresponder a uno u otro Departamento, $u$ otras de carácter funcionarial, apoyadas casi siempre en pretensiones reivindicativas; en otros casos, se trata de establecer el aparato organizativo correspondiente para intervenir y ahormar la propia realidad social. Con frecuencia, también, son razones políticas las que están tras los enunciados organizativos; razones que, en definitiva, responden, simplemente, a un puro problema de reparto del Poder. En cualquier caso, es fácil concluir que cualquiera de estas circunstancias, a la postre, no viene sino a alterar la racionalidad, que también hay, debe haber, una racionalidad polí- 
tica, que es obligada en la formulación de todos los esquemas organizativos del aparato del Poder (1).

Las consideraciones anteriores, de carácter general, pueden servir de pórtico en el momento presente para aproximarnos al estudio de las Diputaciones; también, al de la división provincial. Acaso resulta un tanto inconcebible, pero cabe advertir cómo después de la CE lo relacionado con todas estas cuestiones está resultando en exceso polémico; su análisis, con frecuencia, aparece también en demasía apasionado. Es obligado ser absolutamente sinceros. Se trata de unos planteamientos que, en el fondo, no responden sino a una única finalidad: cuestionar la funcionalidad e, incluso, también, la propia existencia de las Diputaciones provinciales. Un estado de opinión que está ahí; un tanto latente, si se quiere, pero que cadencialmente emerge con una cierta agresividad y que, en cualquier caso -conviene notar-, prescinde de los mandatos, claros por demás, que sobre ello establece el texto constitucional.

Razones muy claras están en la base de esta auténtica animadversión frente a las Corporaciones provinciales, que es fácil percibir desde el momento mismo de la elaboración de la Constitución. Animadversión que, sin embargo, parece remitir en los últimos tiempos. En apoyo de tales planteamientos, además, acostumbran a traerse a colación los tópicos habituales al uso, acerca del carácter convencional y ahistórico de nuestra organización provincial, así como los que no ven en ella sino una mimética reproducción de las soluciones importadas del modelo francés. La absoluta carencia de rigor de estas tesis, que ya he analizado críticamente en otra ocasión (2), hacen que no merezcan la más mínima atención.

(1) El tema de la racionalidad del Poder o, más exactamente, el del desarrollo de este último de acuerdo con el principio citado, constituye uno de los elementos más constantes en la obra de M. WeBER: vid. principalmente, Economía y Sociedad, I, México, 1944, 80 ss y passim. Una referencia sobre el tema en relación con la concreta realidad que ofrece la Administración española, en S. MARTíN-RETORTILLO: El reto de una Administraciỏn racionalizada, Madrid, 1983. y, de modo muy especial, A. NiETO: La organización del desgobierno, Barcelona, 1984 , in totum.

(2) Vid. sobre ello, en concreto, S. MARTÍN-RETORTILLO: En torno a la organización provincial, en Libro homenaje al profesor J. Galván, Valencia, 1980. Trabajo que fue publicado también en RAP, 97.7 ss. La perspectiva histórica es imprescindible para la comprensión del tema; en concreto, para estudiar el proceso de afianzamiento de las Diputaciones Provinciales a lo largo de todo el siglo XIX. En relación con este punto conserva toda su validez el luminoso análisis que realizó E. GARCíA DE ENTERRIA: La provincia en el Régimen local español en Problemas actuales del Régimen local, Sevilla, 1958 (hay edición posterior, Sevilla, 1986). Sobre el referido proceso histórico, vid. en S. MARTín-RETORTILLO: Descentralización administrativa y organización política, Madrid, 1973, en todo el volumen I. Es de gran interés el análisis llevado a cabo recientemente por M. SANTANA MOLINA: La Diputación Provincial en la España decimonónica, Madrid, 1989. Hay que recordar aquí también alguno de los trabajos de A. GUAITA recogidos en el vol., División territorial y descentralización, Madrid, 1975, autor que con notoria insistencia ha venido postulando la validez de las soluciones provinciales como fórmulas de descentralización territorial. 
Razones éstas de las enunciadas antiprovincialistas, nótese, contrarios a lo que establece la CE y a lo que sancionan la casi totalidad de los Estatutos de Autonomía, y que no son sino cobertura, puro pretexto de un problema que es de simple distribución del poder político. En definitiva, se trata de lograr el apoderamiento de unas organizaciones, existentes y consolidadas, por parte de quienes en ellas no detentan el poder político. Explicación de la realidad que refiero y que, en mi opinión, se ha debido a una doble causa.

En primer lugar, y afortunadamente con carácter transitorio, la oposición a las Diputaciones durante las Constituyentes y la 1 Legislatura procedía en esos momentos de los grupos políticos de la oposición. De modo principal, y en contra de su notoria tradición en este sentido, del Partido Socialista Obrero Español. Repasar sobre este particular los testimonios aducidos en los debates parlamentarios sobre el tema resulta realmente expresivo: Las Diputaciones -se decía- eran el «nido del caciquismo antidemocrático», expresión de la "supervivencia del franquismo», "reductos últimos de la reacción», etc. Son, desde luego, significativos. Situación de rechazo que se agravaría como consecuencia de la distribución de los puestos de las Corporaciones provinciales establecido por la Ley 39/1978, de 17 de julio, de elecciones locales que, en la práctica, vino a impedir de forma notoria el acceso al Gobierno de las mismas a los partidos de la oposición. El tema, sin embargo, cambiaría radicalmente como consecuencia de la tan irregularmente tramitada Ley de Elecciones Locales de 2 de marzo de 1983. No obstante, la valoración crítica que me pudo merecer el contenido de esta Ley por la desproporcionada concentración que llevó a cabo de la representación de las capitales de provincia (3), aquélla ha tenido la virtualidad de operar un cambio radical en el posicionamiento del Partido Socialista Obrero Español en este tema. Aceptación ya, desde entonces, de las Diputaciones Provinciales. No entro ni valoro las razones, fundamentalmente electoralistas, que están en la base del cambio operado. Son fáciles de comprender. Lo que me interesa notar es que la Ley citada, con la ordenación que recogía sería cauce importante que permitiría el acceso al poder de las Corporaciones Provinciales a quienes antes no lo habían podido alcanzar. En cualquier caso, el cambio operado es importante. $Y$ como ya señalé (4), en este punto no se trata de ponderar el alcance de determinadas líneas de actuación política, cuanto, sobre todo, de señalar que se alcanzó con ello el reconocimiento y la afirmación institucional de la organización local a nivel

(3) Cfr. S. MARtín-Retortillo: «Presente y futuro de las Diputaciones Provinciales», REDA, 39, $504 \mathrm{~s}$.

(4) Ibidem, 505. 
provincial que, sigo considerando, es elemento fundamental para nuestro desarrollo y para nuestra propia convivencia.

La segunda línea frente a las Diputaciones Provinciales va a ser postulada, básicamente, por algunas fuerzas nacionalistas; de modo principal, y desde un comienzo, por las catalanas (5). Más tarde se asumirá igualmente, y de forma muy explícita, desde algunas Comunidades Autónomas. En cualquier caso, siempre con la intencionalidad de asumir el poder que las Diputaciones pueden ostentar. Apoderamiento de cometidos y competencias de las Diputaciones Provinciales, en lo que, en ocasiones, muchas Comunidades Autónomas han prestado más diligencia y tesón que en el ejercicio de sus propias competencias. Y ello, olvidando el alcance que "para la gestión de sus respectivos intereses» impone el artículo 137 CE a las tres instancias organizativas que allí se anuncian y cuya autonomía se garantiza. No sólo frente al Estado; también frente a la acción mutua de esas tres instancias entre sí. Un planteamiento en el que, como auténtico y permanente ritorneIlo, acostumbra a postularse la sanción institucional de la realidad comarcal (6) que, de este modo, vendría a ofrecerse como auténtica alternativa a la organización provincial. De todos modos, y no obstante la concreción del ámbito geográfico, en el que inicialmente se localizan estos planteamientos, hay que notar que, en ocasiones, han encontrado también eco en otros ámbitos, aislados y muy definidos: En definitiva, y salvo muy excepcionalmente, supuestos en los que la ordenación comarcal puede responder a una realidad cierta, se trata generalmente de alguna de las hipotéticas cabeceras de comarca que de este modo ya pueden alcanzar así una nueva capitalidad, frente a la soportada centralización que, se entendía, ha venido representando siempre la de la provincia.

Las consideraciones expuestas constituyen en cierto modo el contexto real que en nuestros días enmarca el debate en torno a las Diputaciones Provinciales. Expresan las razones que subyacen en el

(5) Frente a la conocida posición que refiero en el texto, vid la ponderada opinión sobre este particular de J. TARRADELLAS "Ja soc aqui». Recuerdo de un retorno, Barcelona, 1990. En relación con esta cuestiones, cfr. también E. ARGULLOL "Las opciones de organizació territorial en Cataluñan, REVL, 228. Sobre el artículo 5 del Estatuto de Cataluña, al que luego me referiré, vid. el comentario de R. ENTRENA CUESTA O Organización territorial en Comentaris sobre l'Estatut d'autonomia de Catalunya, I, Barcelona, 1988, 199 ss.

(6) Cfr. las referencias expositivas que sobre este punto recojo en Presente y futuro, cit. La posición crítica que sostengo respecto a la alternativa provincia versus Comarca, en modo alguno excluye la adopción de soluciones orgánicas supramunicipales de ámbito comarcal, de acuerdo con la conocida fórmula de la comarcalización de servicios: sobre ella, por todos, $M$. CORELLA Competencias provinciales. Análisis de los ámbitos territoriales adecuados para su ejercución en el vol. colectivo, Provincia y Diputaciones provinciales en el Estado de las autonomías, Granada, 1980, 65 s; R. MARTín MATEO, "La concertación competencial de Comunidades Autónomas y Diputaciones», en REDA, 36,5 ss. 
mismo. Es difícil comprenderlo sin tenerlas en cuenta; de ahí que deban estar muy presentes en estas reflexiones. En otro caso, el estudio de la temática referente a la autonomía de las Corporaciones Provinciales y a las relaciones de las mismas con las correspondientes Comunidades Autónomas quedaría a todas luces incompleta. Sería, además, difícil de comprender; la problemática que pudiéramos recoger carecería, en tal caso, de la obligada referencia a las causas reales que han dado lugar a ella.

\section{LA GARANTIA INSTITUCIONAL DE LA PROVINCIA EN LA CE \\ 1. Las Diputaciones Provinciales en el anteproyecto y en el texto de la CE}

No obstante sean conocidos, es obligado aludir, aunque sea brevemente, al tratamiento que del tema ofrecen los dos textos que acaban de enunciarse.

En el anteproyecto de constitución, las Corporaciones Locales se regulaban en el artículo 105 . Este artículo aparecía recogido en un único capítulo dedicado genéricamente a las Administraciones Públicas (7). Se desconocía asi el tratamiento constitucional que es habitual del régimen local $y$, fundamentalmente, nuestra propia tradición histórica; incluso, la Constitución de 1931. Junto a esta valoración de carácter general el anteproyecto, por lo que se refiere a la organización provincial, se manifestaba en términos deliberadamente ambiguos, dejando abierta la posibilidad de que desapareciese la Provincia en cuanto entidad local, y, consiguientemente, las Diputaciones: "Las Provincias -decía- o, en su caso, las circunscripciones que los Estatutos de Autonomía establezcan, mediante la agrupación de Municipios...». Se daba así entrada de modo alternativo a la organización comarcal, reproduciéndose de nuevo el intento que, en análogos términos, se había planteado durante la Segunda República. En aquel entonces, la supresión de las Provincias fue bandera levantada, básicamente, por los radicales, radicalsocialistas, tradicionalistas, sectores regionalistas y por distintos grupos de derecha. Frente a esta postura, la defensa de la Provincia encontró a su favor las mentes más lúcidas de nuestro pensamiento; $y$, entre los grupos políticos, el decidido apoyo del PSOE. En definitiva, y según he destacado en otro lugar (8), fueron

(7) Vid. sobre el tratamiento de la Administración Local $y$, en particular, el de las Diputaciones, en el Anteproyecto de Constitución, S. MARTíN-RETORTILLO "Las Corporaciones Locales en el Anteproyecto de Constitución», en REVL, 197, recogido posteriormente en el vol. Administración y Constitución, Madrid, 1981,201 ss.

(8) Acerca de la suerte que durante las Constituyentes de la II República corriera la llamada enmienda Orozco, con referencia explícita de los Diputados que votaron a favor y en contra de la supresión de las Diputaciones, vid. S. MARTin-RETORTILLo En torno, cit., notas. 
posiciones de carácter marcadamente conservador las que en los albores de la Segunda República plantearon la supresión de la Provincia.

En el trámite de enmiendas al texto constitucional se cuestionó ampliamente el que ofrecía el anteproyecto; también su propio encuadramiento sistemático. $Y$ si se realizó notoriamente todo el tratamiento del régimen local, frente a los planteamientos antiprovincialistas terminó por imponerse el buen sentido, de forma que la Provincia, en cuanto entidad local integrada por la agrupación de Municipios, encontró garantizada su existencia y su contenido esencial en la propia Constitución.

El texto de la Constitución es, en este punto, parco por demás. Parquedad que, sin embargo, no es referible, ni menos aún caracterizadora exclusiva del tratamiento que se ofrece a las Diputaciones Provinciales. Lo es absolutamente de toda la ordenación que se recoge de la Administración Local que, por su parte, queda notoriamente ampliada si se considera que, además de la que se contempla en su singularidad (arts. 140 y 142), hay que entenderla completada con los principios generales que de la organización territorial del Estado ofrece la propia Constitución (arts. 137 a 139), y con la que se deriva de la inequívoca consideración de las Corporaciones Locales como poderes públi$\cos y$, también, como Administraciones Públicas.

Abreviado o conciso, lo cierto es que la ordenación que ofrece el texto constitucional de la Administración Local es por demás rigurosa y definida. Y ello hasta el extremo que no deja ya lugar a dudas (9). En particular, por lo que se refiere al tema de la Provincia, en cuanto la configura como entidad local «determinada por la agrupación de Municipios» (art. 141.1), que necesariamente constituye uno de los grados de la organización territorial del Estado (art. 137), que constitucionalmente tiene además garantizada su "autonomía para la gestión de sus respectivos intereses». Unos enunciados en los que quiero hacer especial hincapié; de modo especial, y como es lógico, por lo que se refiere a la configuración

(9) Cfr. S. MARTIN-RETORTILlo Presente y futuro, cit. 495. El tratamiento constitucional de las Diputaciones provinciales es considerado, lógicamente, en todos los comentarios a nuestra ley fundamental. En particular, deben recordarse las referencias que, en concreto, se recogen en el vol. colectivo La provincia, Granada, 1985, constituido por las Actas del IX Congreso italoespañol de Profesores de Derecho Administrativo. En relación con el punto concreto que ahora refiero, cito las colaboraciones de F. GARRIDO FALLA, R. ENTRENA CUESTA, M. BAENA DEL ALCÁZAR, E. ROCA y, muy principalmente, la de L. MORELL, autor que viene dedicando especial atención al tema de las Diputaciones Provinciales; vid. de este autor, además de los trabajos que se citan en otras notas de este trabajo, El Régimen Local español, I, Madrid, 1988, 93 ss. y 651 ss.; su colaboración, Las Provincias, en S. MUÑoZ MACHADO. Tratado de Derecho municipal, I, Madrid, 1988, asi como El Estado de las autonomías territoriales. Aspectos institucionales, en el vol. colectivo por mi dirigido, Pasado, presente y futuro de las Comunidades Autónomas, Madrid, 1989. 
constitucional de las Diputaciones como entidades determinadas por «la agrupación de Municipios». Calificación ésta que resulta básica, en cuanto de ella habrá que derivar todo el régimen funcional de las citadas entidades. A su vez, es naturalmente de la relación que cabe establecer entre los artículos $141 \mathrm{CE}$ y el. 137, de la que hay que deducir las consecuencias más importantes respecto a la garantía institucional que de las Diputaciones Provinciales sanciona el texto de nuestra Constitución.

\section{Referencia a la doctrina del TC}

Es obligada también, aunque sea muy en síntesis, la referencia a los pronunciamientos más significativos del TC en relación con el tema que estudiamos. En tal sentido, cabe adelantar que, en principio, aquél ha reaccionado en todo momento, tanto frente a los intentos antiprovincialistas de hacer desaparecer las Diputaciones como frente a aquellos otros que postulaban mantener la autonomía provincial en términos puramente formales, declarando siempre la indisponibilidad de la garantía institucional que la Constitución establece.

En primer lugar, fue la conocida STC de 28 de julio de 1981 , relativa al recurso de inconstitucionalidad promovido por el Presidente del Gobierno contra la Ley de Cataluña de 17 de diciembre de 1980, que, prácticamente, suprimía a las cuatro Diputaciones de esa Comunidad Autónoma. La doctrina del Tribunal Constitucional es contundente; no deja lugar a duda. Baste con reproducir aquí alguno de los párrafos del tercero de sus fundamentos jurídicos:

«El orden jurídico-político establecido por la Constitución asegura la existencia de determinadas instituciones, a las que se considera como componentes esenciales y cuya preservación se juzga indispensable para asegurar los principios constitucionales, estableciendo en ellas un núcleo o reducto indisponible por el legislador. Las instituciones garantizadas son elementos arquitectónicos indispensables del orden constitucional, y las normaciones que las protegen son, sin duda, normaciones organizativas, pero a diferencia de lo que sucede con las instituciones supremas del Estado, cuya regulación orgánica se hace en el propio texto constitucional, en éstas la configuración institucional concreta se defiere al legislador ordinario, al que no se fija más límite que el de reducto indisponible 0 núcleo esencial de la institución que la Constitución garantiza. Por definición, en consecuencia, la garantía institucional no asegura un contenido concreto o un ámbito compe- 
tencial determinado y fijado una vez por todas, sino la preservación de una institución en términos reconocibles para la imagen que de la misma tiene la conciencia social en cada tiempo y lugar. Dicha garantía es desconocida cuando la institución es limitada, de tal modo que se la priva prácticamente de sus posibilidades de existencia real como institución para convertirse en un simple nombre.»

El texto, como puede verse, es en extremo preciso. No sólo en lo que se refiere al intento de la posible cancelación de las Diputaciones Provinciales, sino también en cuanto advierte en su última parte que sería igualmente contrario a la Constitución que el legislador ordinario -estatal o autonómico- llevase a cabo una limitación o un vaciamiento tal de sus funciones que, en la práctica, aquéllas resultasen desprovistas de cometidos.

También, y con posterioridad, siempre en la misma línea, hay que considerar la sentencia de 16 de mayo de 1983 habida en el recurso previo de inconstitucionalidad contra el proyecto de Ley Orgánica que modificaba la entonces recién aprobada Ley de Elecciones Locales. En relación con esta sentencia quiero destacar que el fundamento principal del fallo que pronuncia radica, precisamente, en la afirmación y en el reconocimiento de la garantía institucional de las Diputaciones, que no sufre detrimento alguno como consecuencia de la modificación de un criterio eminentemente político, cual es el de alterar el sistema de representación de sus órganos de gobierno. Es esto lo que la sentencia señala. $Y$ lo señala, insisto una vez más, sobre la base argumental expuesta:

"Ciertamente este Tribunal -dice en el sexto de sus Fundamentos jurídicos la citada Sentencia de 16 de mayo de 1983- en su Sentencia de 28 de julio de 1981 en una línea de pensamiento de la que ahora no hay por qué alejarse, estimó que el orden jurídico político establecido por la Constitución asegura la existencia de determinadas instituciones, a las que considera como componentes esenciales, y cuya representación se juzga indispensable para asegurar los principios constitucionales, estableciendo en ellas un núcleo o reducto indisponible por el legislador, garantía que es desconocida cuando la institución es limitada de tal modo que se la priva prácticamente de sus posibilidades de existencia real como institución por convertirse en un simple nombre..."

A estas dos Sentencias debe unirse también la Sentencia sobre la LOAPA, de 5 de agosto de 1983, que, si bien de forma un tanto 
incidental pero en la misma línea que las anteriores y en términos expresivos por demás, refiere que la garantía constitucional de la autonomía provincial en su esfera competencial constituye un aspecto básico del régimen local.

Junto a las tres Sentencias recogidas, hay que referir también la de 27 de febrero de 1987, relativa al recurso interpuesto contra una ley de las Cortes Valencianas que establecía los mecanismos de coordinación e integración de las tres Diputaciones Provinciales de esa Comunidad Autónoma en la planificación de la misma. Nos referiremos a ella más adelante. En cualquier caso, debe señalarse que el TC argumenta en este supuesto desde perspectiva distinta la de los límites que ofrece el ámbito de la autonomía provincial. Un planteamiento que, sin embargo, asume precisamente como punto de partida para el reconocimiento de esa autonomía y de la funcionalidad misma de las Diputaciones Provinciales.

Por último, es obligado aludir también aquí a la muy extensa STC de 21 de diciembre de 1989, relativa a los recursos de inconstitucionalidad interpuestos contra la Ley $7 / 1985$, de 2 de abril, reguladora de las bases del régimen local. No hay en ella, prácticamente, referencias directas al tema de la Provincia que nos ocupa. Lo que principalmente se aborda es el alcance del artículo 149.1.18, que como es sabido, constituye el título habilitante de la Ley citada. No obstante, hay que tener presentes los razonamientos que la Sentencia recoge básicamente, por lo que se refiere al alcance de la autonomía local (FJ, 1) y a la obligada redistribución de los niveles competenciales que siempre conlleva el establecimiento de nuevas entidades locales (FJ, 13) o la reordenación que de ellas puede llevarse a cabo.

Estos son, en síntesis, los pronunciamientos más importantes del TC sobre el tema de las Diputaciones Provinciales desde una perspectiva institucional. La valoración conjunta de los mismos no deja lugar a dudas sobre el reconocimiento y funcionalidad de las mismas en la línea argumental que se ha señalado.

\section{LA AUTONOMIA DE LAS DIPUTACIONES PROVINCIALES EN EL CONTEXTO DE LA AUTONOMIA DE LAS CORPORACIONES LOCALES: SU CONCRECION}

Expuesta la regulación llevada a cabo por la CE y expuestos también, en sus líneas generales, los trazos fundamentales a los que ha venido respondiendo la argumentación del TC, es obligado recoger algunas reflexiones acerca de la autonomía de las Diputaciones Provinciales que, obvio es decirlo, hay que encuadrar en 
los términos que sanciona el artículo 137 CE y, más en concreto todavía, en el contexto que ofrece su consideración en el ámbito genérico de la autonomía de las Corporaciones locales. Es línea argumental que resulta obligada; son dos las consecuencias que de ella se derivan de inmediato. Por una parte, y de acuerdo con lo dicho, cabrá referir a las Diputaciones Provinciales las consideraciones genéricas que se formulen en torno al tema de la autonomia de las Corporaciones locales. También, y en segundo lugar, señalar que lo que acaba de decirse no permite concluir, sin embargo, que el tema tiene un tratamiento idéntico para todas ellas. Es lógico. No cabe olvidar que ha sido en torno a la problemática propia de la organización municipal como se ha llevado a cabo históricamente la construcción de la autonomía de las entidades locales; y también, con carácter general, la que pueden ofrecer entidades de muy distinta naturaleza (10). Es un dato a tener muy en cuenta. De ahí que tanto los estudios de carácter general como, ya más en concreto, aquellos otros que se refieren a la autonomía local (11), pivoten básicamente, como es lógico, sobre la cuestión concreta de la autonomía municipal.

Precisados los extremos anteriores, es obligado plantear la cuestión, como ya se ha indicado, a la vista del artículo $141 \mathrm{CE}$, que, en su apartado 2, sanciona que «el Gobierno y Administración autonómica de la Provincia estará encomendado a las Diputaciones", y que, a su vez, hay que relacionar con el artículo $137 \mathrm{CE}$, que sanciona el principio con carácter general, en relación con las tres instancias en las que necesariamente se articula la organización territorial del Estado. $Y$ ha sido en relación con el último texto, que se ha puesto ya de relieve (12) que la Constitución recoge en él un pronunciamiento que aparece dotado de un énfasis especial: confesadamente, se pretenden dejar sentados nada menos que los principios, la estructura maestra de la propia organización territorial del Estado. Así lo había entendido ya, desde el primer momento, tal y como se vio, el Tribunal Constitucional, al sostener en su Sentencia de 2 de febrero de 1981 que la unidad de la que parte la Constitución en sus artículos 1 y 2 se traduce en una organización para todo el territorio nacional, el Estado, si bien la distribución vertical del poder en el seno del propio Estado determina la participación en el ejercicio de aquél de entidades

(10) Cfr. sobre la articulación técnica del concepto autonomía, con carácter general, por todos, A. EMBID «Autonomía municipal y Constitución: aproximación al concepto y significado de la declaración constitucional de la autonomía municipalı en REDA, 30,452; recientemente también M. SÁNCHEZ MORÓN, La autonomia local. Antecedentes históricos y significado constitucional, Madrid, 1990, en toda su primera parte.

(11) Cfr., además de los trabajos citados en la nota precedente, F. SOSA WAGNER, "La autonomía localn, REVL, núms. 239 y 240.

(12) L. PAREJo, Derecho básico de la Administración Local, Madrid, 1988. 
territoriales de distinto rango, que es justamente lo que expresa el artículo $137 \mathrm{CE}$, de forma que todas las que dicho precepto enumera son «elementos arquitecturales indispensables del orden constitucional».

La autonomía local, en la medida que constitucionalmente se concibe como autogobierno de las distintas Comunidades, bien en primer grado -Municipio-, bien en segundo grado-Diputaciones Provinciales- se ofrece como el lugar idóneo para la manifestación primaria de la participación ciudadana en la vida política, económica, cultural y social que los Poderes públicos están constitucionalmente obligados a promover, así como para la realización efectiva de la libertad e igualdad de los distintos grupos en los que el ciudadano se integra (art. 9.2 CE). Consecuentemente, si esto es así, es preciso proyectar lo que acaba de señalarse a la cuestión central que suscita la regulación constitucional de la autonomía local; esto es, la que se deriva de la referencia que el artículo 137 CE hace al círculo de intereses propios de cada una de las instancias territoriales que enuncia. Criterio referencial que hay que tener siempre muy en cuenta, en relación con el cual debe notarse que ha sido notoria la evolución de la doctrina del Tribunal Constitucional tratando de precisarlo. En primer lugar, y en su Sentencia de 2 de febrero de 1981, al mismo tiempo que señala que son muy distintas las opciones que caben en el concepto de autonomía, recoge también que lo que la Constitución garantiza para cada entidad, "lo es en función del criterio del respectivo interés: interés del Municipio, de la Provincia, de la Comunidad Autónoman, advirtiendo además que

"concretar ese interés en relación con cada materia no es fácil y, en ocasiones, sólo puede llegarse a distribuir la competencia sobre la misma, en función del interés predominante...».

A su vez, en la posterior Sentencia de 28 de julio de 1981 , el TC precisa su posición, insistiendo en que la garantía institucional de la autonomía local debe estar vinculada a un haz de competencias, también vinculadas a ese interés propio, si bien agrega que

«no precisa la Constitución cuales sean esos intereses, ni cuál el haz mínimo de competencias que para atender a su gestión debe el legislador atribuir a la Provincia..." (FJ 3.\%).

El concepto de interés, que es el que constitucionalmente se sanciona, impone y conlleva el de competencia. Estas, además, vienen determinadas por aquél. No obstante, el TC̣ diríase que es 
muy consciente que tal planteamiento puede recordar la tesis tradicional que concebía a los entes locales como entidades naturales, anteriores al propio Estado, hoy insostenible. De ahi que se cuide muy mucho de precisar que no se

«intenta resucitar la teoría de los intereses naturales de los entes locales que, en razón de la creciente complejidad de la vida social, que ha difuminado la línea delimitadora de los intereses exclusivamente locales, avocaría a un extremado centralismo, en consecuencia «la autonomía local ha de ser entendida como un derecho de la comunidad local a participar, a través de órganos propios, en el gobierno $y$ administración de cuantos asuntos le atañen...».

A su vez, en la posterior STC $84 / 1982$, de 23 de diciembre (FJ $4 .{ }^{\circ}$ ) insiste en que

«los entes locales (Municipios y Provincias) tienen autonomía constitucionalmente garantizada para la gestión de sus respectivos intereses (art. $137 \mathrm{CE}$ ); la determinación de cuales sean estos intereses es obra de la ley, que les atribuye, ... consecuencias concretas...».

Las competencias de los entes locales aparecen, pues, como concreción que el legislador ordinario lleva a cabo de los intereses que les corresponden y que refiere el artículo $137 \mathrm{CE}$. Una concreción que, insisto en ello, se remite en cualquier caso al legislador ordinario. Doctrina que en cierto modo refunde el TC en su Sentencia 27/1987, de 27 de febrero (FJ 2..$^{\circ}$ ) al señalar que

"La Constitución garantiza la autonomía de las provincias para la gestión de sus propios intereses (art. 137) encomendando su gobierno y administración a Diputaciones y otras Corporaciones de carácter representativo (art. 141.2). Como este Tribunal ha precisado en repetidas ocasiones (STC 4/1981 y 32/1981, fundamentalmente), dicha autonomía hace referencia a la distribución territorial del Poder del Estado en el sentido amplio del término, y debe ser entendida como un derecho de la comunidad local a participar, a través de sus órganos propios, en el gobierno $y$ administración de cuantos asuntos le atañen, constituyendo en todo caso un poder limitado que no puede oponerse al principio de unidad estatal.

La concreta configuración de la autonomía provincial corresponde al legislador, incluyendo la especificación del 
ámbito material de competencias de la entidad local, así como las fórmulas o instrumentos de relacion con otras entidades públicas y el sistema de controles de legalidad constitucionalmente legítimos.

En primer lugar, la Ley debe especificar y graduar las competencias provinciales teniendo en cuenta la relación entre intereses locales y supralocales en los asuntos que conciernan a la comunidad provincial y sin más límite que el del reducto indispensable o núcleo esencial de la institución que la Constitución garantiza...»

La argumentación es irreprochable. El intérprete constitucional, sin embargo, no deja de reconocer, con justeza, que hay una evidente imprecisión en su propio planteamiento por lo que se refiere al contenido competencial de la autonomía local en general $y$, en concreto, de la autonomía provincial. En definitiva, consecuencia del amplio margen que necesariamente resulta para la capacidad configuradora del legislador ordinario, estatal y autonómico.

Ahora bien, no obstante la amplitud de las opciones que evidentemente puede asumir el legislador ordinario, tal circunstancia no puede suponer una absoluta libertad para la configuración que deber llevar a cabo. Es aquí, como es lógico, donde radica el problema básico del tema que nos ocupa. Una problemática cuya concreción no es desde luego fácil. En cualquier caso, entiendo que la regulación constitucional es suficiente para prefigurar una imagen de la autonomía provincial que enmarque y condicione la tarea posterior del legislador.

En relación con ello, convendrá recordar que el orden constitucional establecido sanciona no sólo el reconocimiento de un tipo de Administración, característico y necesario de la organización local, sino también interpretándolo y valorándolo en su conjunto, en virtud del principio de descentralización administrativa que sanciona, se postula un tipo de Administración en el que, por sus propios valores, tal principio sea utilizado al máximo más allá, incluso, de lo que pueda resultar imprescindible para la atención de las necesidades primarias colectivas de las propias comunidades locales de carácter provincial. Ello significa, en consecuencia, en primer lugar, preferencia por la realización de las tareas administrativas a través de la Administración local; también, reconocimiento a ésta de unos ámbitos competenciales concretos en los distintos sectores del actuar público, estructurado a su vez conforme a la diferente distribución organizativa que sanciona el artículo $137 \mathrm{CE}$. 
La argumentación recogida parece irreprochable. Asumiendo como punto de partida que la CE establece y garantiza la existencia misma de las Diputaciones Provinciales, de tal circunstancia habrá que derivar, lógicamente, que tal reconocimiento algo debe significar, algo debe suponer. Es criterio interpretativo elemental. Un reconocimiento que, con una inequívoca funcionalidad, trasciende los planteamientos estrictamente dogmáticos y nos conduce, ya en el terreno de la práctica, a muy importantes consecuencias. En tal sentido, cabrá referir en primer lugar las competencias provinciales, habida cuenta la configuración de las Diputaciones como entidades locales determinadas "por la agrupación de municipios» (art. 141.1), a conseguir y procurar directamente la plena efectividad de las competencias municipales. Tarea de cooperación, de indudable importancia en una estructura municipal atomizada como es la española. Además, y junto a ello, las competencias de las Diputaciones deben extenderse también a todos los servicios que, en su área de prestación idónea, excedan del ámbito municipal. En estos últimos supuestos, entiendo que no es lo constitucionalmente más correcto atribuir directamente competencias gestoras a instancias superiores a las Comunidades Autónomas, con el doble efecto que ello produce de potenciar un nuevo centralismo, ahora de corte autonómico, y de desplazar así de la gestión de los asuntos públicos a las comunidades locales más directamente interesadas en los mismos.

Las consecuencias que cabe deducir de lo que se viene diciendo, como puede verse, son importantes. Se que, en cierto modo, pueden resultar contrarias a la línea argumental que, con manifiesta claudicación, parece estar de moda en los últimos tiempos. No obstante, guste o no, son el resultado lógico y concluyente del tratamiento que del tema lleva a cabo la CE. Un esquema que como veremos, ha sido asumido, en principio, por la legislación local estatal: expresamente asigna a las Diputaciones la función de «asegurar la prestación integral y adecuada en la totalidad del territorio provincial de los servicios de competencia municipal» [art. 31, a), LBRL]; y también «la prestación de servicios públicos de carácter supramunicipal» [art. 36.1, c)], lo que permite "reservar» a los entes locales $-y$, por tanto, permite su provincialización-, servicios esenciales, alguno de ellos de neto carácter provincial, como la aducción y depuración de aguas, el tratamiento y aprovechamiento de residuos, el suministro de gas, los mataderos, mercados y lonjas centrales, el transporte público, etc. Un planteamiento, y es este dato fundamental a considerar, que debe hacer confluir todas estas funciones directamente en las Diputaciones Provinciales, sin absorción ni intermediación alguna de otras entidades. 
IV. EL TRATAMIENTO DEL TEMA EN LOS ESTATUTOS DE AUTONOMIA; REMISION. LA PROVINCIA EN LA LEY REGULADORA DE LAS BASES DEL REGIMEN LOCAL

El tema es conocido; baste pues, simplemente, con referirlo. Aprobada la Constitución, los sucesivos Estatutos de las 17 Comunidades Autónomas reconocieron explícitamente a la Provincia como entidad local (13). Es cierto que, junto a ello y al amparo de lo dispuesto en el artículo 152.3 CE, aquéllos sancionaron también en ocasiones la posibilidad de establecer organizaciones de carácter comarcal. En cualquier caso, y precisamente por lo que antes se dijo, son significativos los términos en los que se produjo el referido reconocimiento en el Estatuto de autonomía de Cataluña, aprobado por Ley Orgánica 4/1979, de 18 de diciembre: su artículo 5 hace precisamente referencia a la organización territorial de Cataluña en municipios y comarcas, así como en demarcaciones supracomarcales. Ahora bien, este reconocimiento, según se recoge seguidamente, lo es «sin perjuicio de la organización de la Provincia como entidad local y como división territorial para el cumplimiento de las actividades del Estado de conformidad con lo previsto en los artículos 137 y 141 de la Constitución». La precisión es importante. Supone, ni más ni menos, que el reconocimiento explícito de las Diputaciones, al que, obviamente, es preciso dar un sentido y un alcance. Una valoración que todavía se realza más si se considera que las referencias que acabo de recoger a la Provincia como entidad local fueron expresamente introducidas durante la tramitación parlamentaria del texto, ya que no figuraba en el proyecto de Estatuto presentado a las Cortes.

La organización provincial se contempla en los distintos Estatutos como algo diferenciado de la organización de las Comunidades; y diferenciado, también, de la organización territorial del Estado. Y ello, sin perjuicio de que algunas de aquéllas asuman también la división provincial como base territorial de su propia organización. Realidad organizativamente heterogénea que, sin embargo, no empece, como es lógico, a que, tal y como se verá, deban establecerse las correspondientes relaciones entre las distintas instancias territoriales que habrán de operar desde luego a muy distintos niveles. No podía ser de otra forma.

(13) Las referencias sobre este particular de los distintos Estatutos de Autonomia, que no parece necesario reiterar ahora acostumbran a estar recogidas en todas las recientes colecciones legislativas en materia local: vid., entre otras, la ed. de L. COSCULLUELA Legislación de Régimen Local, Madrid, 1990. El tema concreto del papel de las Diputaciones Provinciales en el contexto de las Comunidades Autónomas ha sido objeto de distintos estudios: vid., además de mi trabajo cit. nota 3, L. MORELL OCAÑA, «La provincia en la configuración y ordenación territorial de las Comunidades Autónomas», en REDA, 31; A. EMBID IRUJO, "Las relaciones de las Comunidades Autónomas y la estructura de la Administración Local», RAP, 34. 
Es este último planteamiento el que precisamente recoge la Ley 7/1985, de 2 de abril, reguladora de las Bases del Régimen local. El texto, sin embargo, no es mucho el realce que ofrece de las Diputaciones Provinciales. En su catequética e historicista Exposición de Motivos, apenas si se las refiere. $Y$, sin perjuicio de reconocer las fundadas y lógicas diferencias que existen, hay en aquél un expreso y notorio interés de realzar el significado del Municipio frente a la Provincia: la Ley se abre con el pórtico de su artículo 1, que proclama que el Municipio es la entidad básica de la organización territorial del Estado y cauce inmediato de participación ciudadana en los asuntos públicos, mientras que, por lo que a la Provincia se refiere, se limita a garantizar su «autonomía para la gestión de los intereses respectivos» (art. 1.2). Es cierto que se reconoce a la Provincia su derecho a intervenir en cuantos asuntos afecten directamente al círculo de sus intereses (art. 2.1). No obstante, y en la línea que señalo, la Ley asume un muy distinto tratamiento por lo que se refiere a la fijación del régimen competencial de Municipios y Provincias. En relación con los primeros, y desde la vis específica que, según su Exposición de Motivos, tiene precisamente esta Ley, les garantiza explícitamente unos determinados ámbitos de la actividad pública en los que las Leyes sectoriales, estatales o autonómicas les deben reconocer siempre competencias decisorias (art. 25.2). Hay también unas competencias-deberes -obligaciones mínimas-, que los mismos deben ejercer y garantizar, por sí o asociados o con la cooperación de la Diputación Provincial respectiva (art. 26). En relación con las Diputaciones, el enunciado del tema es, sin embargo, muy distinto: en contra del principio de atribución general de competencias con que se caracteriza el Municipio (art. 25.1), se sienta ahora el criterio de la competencia tasada: sólo podrá ejercer como propias aquéllas que le atribuyan las Leyes, garantizándose -como ese núcleo esencial e irreductible al que se refería el Tribunal Constitucional en las Sentencias antes referenciadas- la coordinación de los servicios municipales; la asistencia y la cooperación a los Municipios, y la prestación de servicios públicos de carácter supramunicipal o supracomarcal (art. 36.1). Es cierto que, como finalidad de las Diputaciones, como ya se ha dicho, se les asigna "garantizar los principios de solidaridad y equilirio intermunicipales», asegurando la prestación integral y adecuada en la totalidad del territorio provincial de los servicios de competencia municipal [art. 31.2, a)]. El enunciado es desde luego escueto; no obstante, puede resultar de interés aunque se formule a través de una auténtica cláusula general cuya integración concreta resulta siempre difícil de precisar. En cualquier caso, al hacerlo es obligado, según se dijo, no introducir 
intermediación ni sustitución orgánica de ningún tipo en la atribución de las competencias que requiere el ejercicio de esas funciones.

Junto a lo dicho, no cabe desconocer tampoco que la Ley reguladora de las Bases del Régimen local faculta a las entidades locales en general para ampliar sus competencias, mediante expediente municipalizador o provincializador, a aquellos servicios esenciales que la Ley expresamente declara reservados a su favor (art. 86.3); igualmente ha de tenerse en cuenta que, junto a las competencias propias se prevé igualmente que el Estado y las Comunidades Autónomas pueden delegar competencias en las Diputaciones, así como que aquéllas encomienden a éstas la gestión ordinaria de servicios propios, en los términos previstos en sus Estatutos respectivos (art. 37), en armonía con las previsiones que al respecto estableció la Ley del Proceso Autonómico, de 15 de octubre de 1983. Son desde luego importantes las posibilidades que por esta vía se ofrecen a las Diputaciones. No cabe negarlo. En cualquier caso, hay que observar que tales posibilidades se mantienen en el orden de las simples hipótesis: actuaciones factibles, no necesarias. Actuaciones que, en definitiva, son siempre a resultas de lo que otras entidades puedan decidir. $Y$, en principio, no parecen muy propensas a renunciar o delegar el ejercicio de la más mínima parcela de Poder...

\section{LA COORDINACION DE LAS COMPETENCIAS PROVINCIALES POR LAS CORRESPONDIENTES COMUNIDADES AUTONOMAS}

\section{Consideraciones generales}

La Ley reguladora de Bases del Régimen local, al reconocer la autonomía de los entes locales, se cuida de precisar también de modo expreso y con carácter general que el ejercicio de las competencias propias de los mismos debe hacerse con la «debida coordinación en su programación y ejecución con las demás Administraciones Públicası) (art. 7.2). Es lógico. En desarrollo de dicho principio, la Ley faculta a las Comunidades Autónomas para asegurar, en su respectivo territorio, la coordinación de los diferentes planes provinciales que elaboren y aprueben las Diputaciones Provinciales [art. 36.2, a)]. En relación con ello, concretándolo, precisa también en su artículo 10.2 que

«procederá la coordinación de las competencias de las entidades locales entre sí, y especialmente con las de las 
restantes Administraciones Públicas, cuando las actividades o los servicios locales trasciendan el interés propio de las correspondientes entidades, incidan o condicionen relativamente los de dichas Administraciones o sean concurrentes o complementarios de los de éstas».

A tal fin, se articulan (arts. 57 y 58 ) diversos mecanismos de coordinación (convenios, consorcios, órganos de coordinación o encuentro); y como última ratio o instrumento excepcional para hacer efectivo algo que resulta tan lógico $y$ natural dispone el artículo 59 que

"A fin de asegurar la coherencia de la actuacion de las Administraciones Públicas en los supuestos previstos en el artículo 10.2, para el caso de que dicho fin no pueda alcanzarse por los procedimientos contemplados en los artículos anteriores o éstos resultaren manifiestamente inadecuados por razón de las características de la tarea pública de que se trate, las Leyes del Estado y de las Comunidades Autónomas, reguladoras de los distintos sectores de la acción pública, podrán atribuir al Gobierno de la Nación o al Consejo de Gobierno la facultad de coordinar la actividad de la Administración local y, en especial, de las Diputaciones Provinciales en el ejercicio de sus competencias...»

El texto transcrito ofrece una doble vertiente. Por una parte, necesidad que las Leyes estatales o autonómicas atribuyan a una instancia superior esas facultades de coordinación. Necesidad y, también, en segundo lugar, posibilidad. La puesta en práctica de tal solución, como es fácil de adivinar, requiere ser en extremo meticuloso, ya que a través de esta vía puede procederse igualmente a ese vaciamiento competencial de las Diputaciones Provinciales al que venimos aludiendo; en definitiva, y por lo que a este punto se refiere, todo dependerá del alcance y virtualidad que se dé al citado principio de coordinación. Se trata de un extremo que es preciso plantear con absoluta claridad. $Y$ ello porque al socaire de una exigencia lógica, como la que expresa el citado principio, en la práctica están reduciéndose las competencias efectivas de las Corporaciones Provinciales. En relación con ello, cabe observar que frustrada cualquier tipo de pretensión de las Comunidades Autónomas de cancelar las Diputaciones Provinciales, aquéllas han encontrado en el principio de coordinación no sólo un título para relacionar el ejercicio de determinadas competencias, sino también, en ocasiones, para desapoderar de ellas a las Diputaciones Provin- 
ciales existentes en su territorio. El intento ha sido reiterado. No por ello parece justificado. En cualquier caso, debemos referir algunos supuestos.

El primero, una vez fracasada la operación de suprimir las Diputaciones catalanas como consecuencia de la citada STC, fue el de la Comunidad Valenciana, que desarrollaría las previsiones contenidas en su propio Estatuto (art. 47.3) en términos muy semejantes a los que después sancionará la Ley reguladora de Bases de Régimen Local. Es la Ley de las Cortes valencianas de 4 de octubre de 1983 por la que se declaran de interés general por la Comunidad Valenciana determinadas funciones propias de las Diputaciones Provinciales. El enunciado de la Ley debe notarse, aparece muy en consonancia con las argumentaciones recogidas por el TC y por sí sólo, resulta por demás significativo. La Ley vino a establecer muy concretos mecanismos de integración, prácticamente, de la total actividad de las Diputaciones en la planificación decisoria de la Generalidad Valenciana. La fórmula utilizada era de una simplicidad extrema: Se declara de interés para la Comunidad la actuación de las Diputaciones, con lo que aquélla avoca para sí no pocas competencias decisorias de estas últimas. La solución, por la amplitud de las funciones que al socaire de sus cometidos de coordinación de las Diputaciones, pasaba a desempeñar la Comunidad parecía realmente excesiva (14). No lo entendió así la STC 27/1987, de 27 de febrero, al resolver, desestimándolo, el recurso de inconstitucionalidad interpuesto por 53 Senadores que, sin embargo, reconoció que, en principio

«el ámbito material u objetivo de la coordinación autónoma de las Diputaciones Provinciales valencianas, por amplio que sea, tiene sus límites. De un lado, la coordinación está asimismo objetivamente limitada por la imprescindible concurrencia de los presupuestos legitimadores establecidos en el apartado $2 .^{\circ}$ del citado artículo $2 .^{\circ} \ldots$...

El Tribunal Constitucional entendió, pues, ajustada a la garantía institucional de la autonomía provincial la Ley impugnada, "siempre que se interprete de acuerdo con las previsiones del artículo 10.2 de la Ley de Bases del Régimen Local». Concreción importante, en

(14) Una valoración crítica de esta Ley de las Cortes Valencianas, expresamente, en S. MARTín-RETORTILLo Presente y futuro, cit. $513 \mathrm{~s}$; la razón en la que me apoyaba no era sino la de que el título de intervención que supone la actividad coordinadora que se encomienda a la Comunidad, aparece referido a la práctica totalidad de las competencias de las Diputaciones. Desaparece así el concepto de interés propio de estas Corporaciones que garantiza el artículo $137 \mathrm{CE}$. Un planteamiento que, como es sabido, no fue acogido por el TC, tal y como seguidamente refiero en el texto. No obstante, la Sentencia vino a introducir determinadas cautelas interpretativas, de evidente salvaguarda de las competencias provinciales. 
cuanto, diríase, que el propio Tribunal es muy consciente de los riesgos que tal solución puede comportar, ya que no vacila en advertir también la posibilidad de que uen la aplicación de dicho precepto pueda infringirse la Constitución o las demás normas que componen el bloque de constitucionalidad..." (FJ 5.\%).

Sancionada de este modo la constitucionalidad de la intervención coordinadora de las Comunidades Autónomas sobre la actuación de las Diputaciones Provinciales, con contenido distinto, se han aprobado Leyes en tal sentido, entre otras, en las Comunidades de Aragón (Ley 8/1985, de 20 de diciembre), Castilla y León (Ley 6/1986, de 6 de junio) y Andalucía (Ley 11/1987, de 26 de diciembre). En todas ellas, junto a la coordinación señalada que, en principio, se asume con una extensión notoriamente más ponderada a como se recogía en la Ley de las Cortes valencianas, se lleva a cabo también, consecuentemente, una delimitación de las competencias de las Diputaciones Provinciales que, de modo principal, se centran en la cooperación y coordinación de los servicios municipales, asistencia y cooperación a los Municipios y en la prestación de algunos servicios de carácter supranacional $y$, en su caso, supracomarcal.

2. La Ley de Cataluña 5/1987, de 4 de abril, de régimen provisional de las competencias de las Diputaciones Provinciales y la alternativa comarcal recogida en la Ley 6/1987, de la misma fecha

En 1987 la Comunidad Autónoma de Cataluña ha aprobado diversas Leyes relacionadas con el régimen local. Una, de carácter general (Ley 8/1987, de 15 de abril); otra, polémica por demás. sobre las actuaciones públicas en la conurbanación de Barcelona (Ley 7/1987, de 4 de abril); otra, sobre la organización comarcal (Ley 6/1987, de 4 de abril), y, por último, una sobre régimen provisional de competencias de las Diputaciones Provinciales (Ley 5/1987, de 4 de abril). Todas ellas constituyen obviamente una ordenación global que es preciso considerar en su conjunto. No obstante, y como es lógico, aquí debemos detenernos de modo especial en la última de las Leyes citadas. Su comprensión real, sin embargo, requiere tener muy en cuenta la anterior Ley de la misma Comunidad de 17 de diciembre de 1980, cuya inconstitucionalidad fue declarada, como se dijo, por la STC de 28 de julio de 1981, pronunciamiento al que, en cierto modo, esta Ley 5/1987 trata de dar respuesta.

El artículo $1 .^{\circ}$ de la Ley 5/1987 señala que la Ley tiene por objeto 
«regular el régimen provisional de las competencias de las Diputaciones Provinciales catalanas y el ejercicio de dichas competencias, mientras no se produzcan las condiciones legales que hagan posible que el Gobierno y la Administración de las provincias se integren en la Generalidad, con la consiguiente desaparición de la división de Cataluña en provincias».

La intencionalidad que se pretende no puede ser, pues, más explícita. Se trata, según expresa la Disposición adicional primera, de instar la alteración de la actual división de las cuatro provincias para que, mediante Ley Orgánica (art. $141 \mathrm{CE}$ ), se cree una sola provincia en toda Cataluña, cuyo gobierno y administración correspondería así a la Generalidad, al convertirse en Comunidad uniprovincial (art. 141.2 CE), de modo que entonces concurrirían en ella necesariamente las funciones de la Diputación Provincial. El artículo $2 .^{\circ}$ de la Ley, por su parte, se limita a enunciar las vías en que se concreta el régimen provisional que se establece -atribución de las competencias de las Diputaciones Provinciales a las comarcas, y establecimiento de instrumentos de coordinación de las competencias provinciales residuales-, que deberá hacerse efectivo mediante las correspondientes Leyes del Parlamento de Cataluña (art. $4^{\circ}{ }^{\circ}$. No obstante, se indica que la reasignación de competencias provinciales deberá llevarse a cabo respetando «el núcleo esencial de la autonomía provincial» (sic) y, por tanto, no podrá afectar a las competencias provinciales de uasistencia y cooperación jurídica, económica y técnica que corresponden» a aquéllas (art. $\left.4^{\circ}, 1\right)$, que, según se dice, son las competencias provinciales que reconoce la Ley reguladora de las Bases de Régimen Local y la Ley 8/1987, Municipal y de Régimen Local de Cataluña, en su artículo 88. Un enunciado que resulta por demás equívoco. Y ello porque reduce los cometidos de las Diputaciones Provinciales a esas funciones de asistencia, en contra de lo que cabe derivar de la propia Constitución y de lo que explícitamente recogen también los dos textos legales que precisamente se citan, en los que, además de tales funciones, de modo expreso se refiere igualmente que las Diputaciones puedan prestar servicios propios. En cualquier caso, la reserva que hace la Ley 5/1987 del núcleo esencial de funciones que se reconocen a las Diputaciones diríase que tiene un carácter cautelar, de alcance puramente formal: No cabe darle otro. Es fácil constatar que resulta casi inviable, o al menos de una complejidad extrema, poder compaginar las funciones provinciales que se señalan, con las que el artículo 82.2 de la Ley $8 / 1987$ asigna a la comarca a la que 
«corresponde [...] realizar actividades y prestar servicios públicos de interés supramunicipal. Le corresponde asimismo asegurar el establecimiento de los servicios municipales en el territorio de la comarca y el ejercicio de las competencias municipales...».

Se trata, como puede verse, de una reproducción casi literal de las funciones que la legislación del Estado atribuye precisamente a las Diputaciones Provinciales, y que la Ley 8/1987 asigna a la comarca. De ahí que, quizá para salvaguardar, también formalmente, el núcleo competencial propio de las Diputaciones, la citada Ley 6/1987, de Organización Comarcal, introduce en su artículo 33, en relación con las funciones anteriores, una cláusula de estilo, también de carácter eminentemente precautorio: Las competencias que se atribuyen a las comarcas se ejercerán usin prejuicio de las competencias que en este ámbito correspondan también a las Diputaciones Provinciales».

Como puede verse, y cualquiera que sea el juicio que se tenga respecto de la futura integración de las cuatro Provincias catalanas en una sola, así como sobre la corrección constitucional de las soluciones expuestas, es lo cierto que resulta difícil poder concluir que tales soluciones respetan el núcleo esencial de la autonomía provincial que la Constitución garantiza. Aparte, la superposición y concurrencia de estructuras organizativas que se establecen para el cumplimiento de unos mismos cometidos (15), cauce siempre ideal para la ineficacia administrativa, sin olvidar tampoco los costos que conlleva.

Es como puede verse, la ordenación comarcal la que, una vez más se asume como alternativa a la fórmula de las Diputaciones Provinciales. En relación con ello conviene salir al paso frente a quienes, con carácter general, defienden la realidad natural de la comarca, frente al significado artificial de la Provincia. No niego, naturalmente, que aquéllas constituyan un hecho real. Nadie medianamente razonable podría hacerlo. Lo que por el contrario se plantea es que, salvo en supuestos muy excepcionales, la determinacion de las comarcas, a la postre, no resulte tan artificial como la de cualquier otra división territorial. Consecuentemente, que las

(15) La Ley 6/1987, de Cataluña, relativa a la organización comarcal, hay que entenderla como contrapunto de la que lleva número precedente, la $5 / 1987$, sobre régimen provisional de las competencias de las Diputaciones Provinciales. La superposición de esquemas organizativos resulta notoria. La comarca, se configura en aquella Ley, también, como «entidad local de carácter territorial formada por la agrupación de municipios contiguos) (articulo 3,1). En cualquier caso, la gestión participativa en la misma, es notoriamente inferior a la de las otras Corporaciones Locales, a la vista de las importantes funciones ejecutivas que se asignan a su órgano unipersonal y no representativo, el Gerente, que se sitúa al frente de toda la Administración comarcal. 
mismas puedan ser base adecuada para establecer una organización administrativa de caráctr general como alternativa fundada a la de las Diputaciones Provinciales. Es cierto que, desde una perspectiva estrictamente funcional, «no tiene defensa fácil la coexistencia en un Estado de dimensiones territoriales medias como España, de cuatro niveles territoriales de gobierno (cinco en las islas) y la posibilidad de añadir un sexto en las comarcas..." (16). Ahora bien, el dilema está en la introducción de nuevos esquemas organizativos o en, rectificándolos en lo que fueren preciso, asumir los ya existentes. Los que como alternativa de estos últimos se presentan no ofrecen, desde luego, mayor racionalidad, constituyen un intento cuya eficacia no sólo no ha sido nunca acreditada, sino ni siquiera constatada $y$, a la postre, no son sino expresión de una bucólica y un tanto ahistórica interpretación del pasado.

Es obligado ser precisos y rigurosos en lo que acabo de señalar. También en el análisis de las soluciones que se pretenden introducir. De ahí que, en relación con la experiencia concreta que ahora considero, convendrá recordar que como ha destacado Martín Mateo (17), la comarca no ha sido ni ues la quintaesencia de Cataluña; la comarca en toda Europa ha sido premunicipio, preorganización, respondía a la organización feudal por condados [...] la comarca era el trasunto de una organización económica simple, de mercados primarios accesibles...». Y este mismo autor ha recordado (18) cómo «los Diputados catalanes en las Cortes de 1821-1822 se opusieron ciertamente con energía a todo lo que pudiera suponer desmembramiento o pérdidas territoriales para el Principado, pero la Diputación de Cataluña se expresó rotundamente a favor de la urgencia y necesidad de que se realice con la mayor prontitud la división provincial que se reclaman, al constatar la imposibilidad de que una sola Diputación pueda atender a toda Cataluña, precisándose por Oliver que «no sólo nos hemos conformado todos los Diputados catalanes con lo que se propone para la división del antiguo Principado, sino que puedo asegurar al Congreso que la Diputación se ha anticipado a revisar los límites de las cuatro Provincias» (19). Es lo cierto que, posteriormente, en las Bases de Manresa (1892) se aludirá ya a la "comarca natural» (Base 5.\%). Se trata de un enunciado que, sin embargo, tal y como se ha

(16) Cfr. J. SantamaRiA. Fundamentos de Derecho Administrativo, Madrid, 1988, 1160; este mismo autor se habia expresado ya anteriormente en términos análogos en «Notas sobre la Sentencia de las Diputaciones Provinciales»), REDA, 34.

(17) Vid., R. MARTIN MATEO La comarca y prestaciones de servicios públicos, en La Comarca y la Administración territorial, Granada, 1986, 74.

(18) Cfr., R. MARTin MATEO Entes locales complejos, Madrid, 1987, 129.

(19) También resultan en extremo aleccionadores los testimonios que, resultado de la consulta que se formuló a la Nación para proceder a la elaboración de la Constitución de Cádiz, recoge M. ARTOLA, Los orígenes de la España contemporánea, II, Madrid, 1959. 
puesto de relieve (20), hay que situar históricamente en sus justos términos: a lo largo del siglo XIX, "el movimiento comarcalista de Cataluña generó abundantes estudios sobre demarcaciones comarcales: en 1864, los de Cebrià y Costa; en 1887 el estudio de Aulestia i Pijoan, y en 1895 el de Flos i Calcat. Examinados estos estudios, se llega sin embargo, a una conclusión desoladora. Todos parten de la misma perspectiva; concretamente, de la concepción de la comarca como un ente de naturaleza histórica. Todos estos autores miran la historia catalana, y de ella deducen una demarcación concreta, pero -y ahí viene lo descorazonador- las conclusiones de estos tres autores son fundamentalmente distintas entre sí. En en el siglo xx cambia por completo el signo. Ya no se habla de un criterio de lo natural. La comarca no es un fenómeno natural -sea histórico, sea geográfico-, sino que se monta artificialmente sobre el criterio de la funcionalidad administrativa, y desde esta perspectiva surge un estudio fundamental: "El problema comarcal de Cataluña" de 1931, inspirado por Pau Vila». Un proyecto (21) que, no cabe olvidar, encontró una muy seria oposición, concitando las protestas de las poblaciones que se creían perjudicadas $y$, precisamente, la de los socialistas que temían que con ello se operase un refuerzo del caciquismo. Será sólo en 1936, ya en plena guerra civil, cuando tal solución obtendría luz verde. En cualquier caso, como ha recordado J. R. Parada (22) fuera de ciertos antecedentes imprecisos, «la reivindicación comarcal catalana no ha podido ofrecer un solo dato o argumento de que la comarca haya sido un hecho político o administrativo, una organización pública que el municipio constitucional o la división provincial haya arruinado o suplantado con su implantación en el siglo XIX॥.

La Ley catalana 6/1987 asume la división comarcal de 1936 como base para la consulta a realizar a los Municipios (art. 5.2), pese a que la Cataluña actual tiene poco que ver con la situación que presentaba en la II República. De ahí que la propia Exposición de Motivos de la Ley 6/1987 no pueda dejar de aludir a que, acaso, «no podría descartarse un rechazo popular por falta de identificación con la nueva división propuesta».

Es la que acabo de referir la realidad cierta; y ello, por mucho énfasis con que ahora se asuman los planteamientos comarcalizadores, que nunca han sido una realidad. En su enunciado, es fácil advertir que, más que la continuidad de una experiencia histórica,

(20) Vid. A. NIETo Legislación del Parlamento de Cataluña sobre comarcas en La Comarca como ente territorial, Barcelona, 1984, 120

(21) Cfr. sobre ello R. MARTin MATEO. Entes locales, cit. 190; vid., también la edición La divisió territorial de Catalunya, ed. de la Conselleria d'Economia de la Generalitat de 1937 de la que hay reedición facsímil de 1977 que, desde Caracas, prologa el propio Pau VILA.

(22) Vid. R. PARADA Derecho administrativo, II, Madrid, 1989, 93 ss. 
que no la ha habido o más que un criterio de racionalización, que tampoco lo presenta, no está excluido que en el fondo de estos planteamientos no haya sido el intento de acentuar el hecho diferenciador de Cataluña en relación con el resto de España. $Y$ también el intento de la Comunidad de ostentar, prácticamente en solitario, el ejercicio del Poder en todo su territorio. Un intento, pues, que aparece fundado exclusivamente en criterios políticos frente a los que hay que advertir que la Constitución ha optado por un muy preciso sistema de Administraciones locales en tres niveles: dos, el Municipio y la Provincia, de carácter necesario; también la comarca, con carácter optativo. Y sin negar las posibilidades que, en su caso, puede ofrecer la ordenación de estas últimas, es lo cierto que cuando la misma supone la desaparición práctica de uno de los niveles necesarios en favor de otro que no lo es, no puede entenderse sino como una auténtica vulneración constitucional. Máxime, insisto, cuando el escalón organizativo que se cercena es de los establecidos con carácter indisponible por la propia CE.

\section{LAS DIPUTACIONES COMO ADMINISTRACION PERIFERICA DE LAS COMUNIDADES AUTONOMAS}

Las Diputaciones han sido orgánicamente sustituidas por los órganos de gobierno de las Comunidades Autónomas en las de carácter uniprovincial (art. 40 de la Ley 7/1985). Es lógico. En Canarias y Baleares, los Cabildos y Consejos asumen las competencias provinciales (art. 41 de la Ley 7/1985) a la vista de una realidad física inequívoca e indiscutible. En el País Vasco, por su parte, las Diputaciones forales de los Territorios históricos tienen un régimen especial y peculiar (Ley 27/1983, de 25 de noviembre). En las restantes Comunidades, sus Estatutos de autonomía, como se ha dicho, reconocen a la Provincia como entidad local y en no pocas la sancionan también como división territorial que expresamente se asume para la Administración autonómica, del mismo modo que el artículo 141 CE la considera en el mismo sentido para la Administración del Estado. En la mayor parte de Estatutos se prevé también la delegación o asignación de competencias ejecutivas de la Comunidad Autónoma a las Diputaciones Provinciales, de forma que éstas sean el órgano ordinario de gestión de sus servicios periféricos: así los artículos $4.3, b$ ), y 4.4 del Estatuto de Andalucía; el artículo 45 del de Aragón; el artículo 30 del de Castilla-la Mancha; el artículo 19 de Castilla y León; el artículo 16.2 del de Extremadura; el artículo 41 del de Galicia, y el artículo 47 de 
la Comunidad Valenciana. Volveré más adelante sobre los términos con que se expresan todos estos textos estatutarios.

El Informe de la Comisión de Expertos sobre Autonomías llamó ya la atención sobre el grave riesgo de que las Comunidades Autónomas decidieran reproducir en su propio espacio los esquemas organizativos de la Administración del Estado; y, en concreto, advertía que

«la formación de un aparato administrativo extenso debe evitarse tanto en los niveles centrales como en los periféricos. La mayor parte de las provincias que van a quedar integradas en las nuevas Comunidades Autónomas soportarían mal que a la antigua centralización estatal sucediera una nueva centralización regional [...]. Las Diputaciones deben quedar convertidas en el escalón administrativo intrarregional básico: es preciso fortalecer sus servicios, dotarlas mejor, integrar en su organización los servicios periféricos de que se ha de desprender la Administración del Estado, para que puedan asumir el ejercicio de competencias por transferencia o delegación de las Comunidades Autónomas y atender ordinariamente la prestación de los servicios que están encomendados a la gestión regional».

Auténtica llamada al buen sentido, directamente fundamental en la idea de no aumentar el aparato administrativo -con el costo económico que ello supone que, con frecuencia, no se pondera debidamente-, y en la de aprovechar al máximo los esquemas organizativos existentes $y$, también, no cabe la menor duda, de hacerlos más eficaces. Es este último un dato muy a tener en cuenta. En definitiva, la Comisión postuló que, en el fondo, no eran sino consecuencia directa de lo que, con fórmulas distintas, habian asumido, como ya se vio algunos de los Estatutos de Autonomía (23); principalmente, desde los de galicia y Andalucía, que encomendaban a las Diputaciones Provinciales, siempre bajo la lógica supervisión y dirección de la correspondiente Comunidad, la gestión ordinaria de las competencias de estas últimas en el ámbito de las correspondientes provincias. La fórmula, en cierto modo, venía a constituir el lógico contrapunto de las obligadas funciones de coordinación de la actividad de las Diputaciones a llevar a cabo por las Comunidades Autónomas.

En consonancia con las ideas señaladas, la Ley del Proceso Autonómico de 1983, en su artículo 5, estableció que las Leyes de

(23) El tema lo consideré con cierto detalle en S. MARTín-RETORTILLO Presente y futuro., cit. 495 
las Comunidades Autónomas podrían transferir a las Diputaciones competencias propias, o delegarles su ejercicio, pudiendo asumir las Diputaciones la gestión ordinaria de los servicios periféricos propios de la Administración autónoma. En parecidos términos se expresan también los artículos 7, 3; 8 y 37 de la Ley 7/1985, reguladora de las Bases del Régimen Local.

Refiramos algunas de las experiencias prácticas a que han dado las posibilidades que acabamos de referir.

En la línea expuesta, y en desarrollo del artículo 4, 4, de su Estatuto, la Comunidad andaluza aprobó la Ley 3/1983, de 1 de junio, "de organización territorial», en la que se expresa que «las competencias de la Administración de la Comunidad Autónoma podrán ser delegadas o asignadas para la gestión ordinaria de sus servicios» en las Diputaciones Provinciales u otros entes locales (artículos 16, 17 y 21). Se trata, en definitiva, que la Comunidad Autónoma articule y desarrolle sus servicios periféricos a través de las Diputaciones (artículo 21, 2). Lo cierto es, sin embargo, que sin derogar expresamente esta Ley, la misma Comunidad ha aprobrado posteriormente la Ley $11 / 1987$, de 26 de diciembre, ureguladora de las relaciones entre la Comunidad Autónoma de Andalucía y las Diputaciones Provinciales de su territorio», en la que se reconocen como competencias propias de las Provincias, la cooperación y coordinación de los servicios municipales, la asistencia y cooperación a los municipios y la prestación de los servicios públicos de carácter supranacional que la propia Ley determina (artículo 15). La Ley asigna además como competencias propias de las Diputaciones, determinadas funciones en materia de cultura (artículo 20), deporte (artículo 21) y turismo (artículo 22). En cambio, va a establecer, por el contrario, que la Comunidad Autónoma asuma la titularidad directa de distintas competencias hasta ahora de las Diputaciones (artículos 25 y 26), cuyo ejercicio, sin embargo, puede después delegarse en las mismas (artículos 29 y 40). El cambio que ello supone es realmente notable. A mayor abundamiento, desaparece en la Ley toda referencia a las competencias asignadas, es decir, a la posible actuación de las Diputaciones como Administración periférica de la Comunidad. Es más; ésta por Decreto 105/1988, de 16 de marzo, ha organizado con notoria amplitud su propia Administración periférica, prescindiendo totalmente de aquéllas y estableciendo en cada provincia de su territorio Delegaciones de Gobernación; Fomento y Trabajo; Hacienda y Planificación; Obras Públicas y Transportes; Agricultura y Pesca; Salud y Servicios Sociales; Educación y Ciencia, y Cultura: delegaciones que en el ámbito territorial de cada provincia ejercen los cometidos de las Consejerías de que dependen. 
En Castilla y León, con notoria ponderación, el Decreto $225 / 1988$, de 7 de diciembre, ha creado en cada una de las provincias, una Delegación Territorial de la Junta de Castilla y León. Se trata, sin embargo, de una representación globalizada de esta última, sin perjuicio de que la Ley 6/1986, de 6 de junio, habia previsto ya la delegación de competencias autonómicas en las Diputaciones Provinciales y en municipios de más de 20.000 habitantes a través de un procedimiento en el que «la Comunidad articula con las Entidades locales la gestión ordinaria de sus servicios periféricos» (artículo 11,2), en los términos que prevé el artículo 20, 2, del Estatuto.

En Valencia la Ley 5/1983, de 20 de diciembre, ha previsto también la creación de servicios territoriales de la Comunidad.

En otras ocasiones, esta creación ha seguido el cauce propio de la reorganización de la estructura de una Consejería concreta de la Comunidad, generalmente la de Presidencia, a través de la que se establecen los órganos periféricos en la propia Comunidad. La inflación del aparato organizativo, en líneas generales, ha sido, pues, notable. De modo especial en algunas Comunidades: tal es el supuesto de la de Galicia, en la que, a tenor del Decreto 5/1987. de 14 de enero, además de las Delegaciones Provinciales de la Xunta se han creado también Delegaciones comarcales y locales de la misma.

Son éstas, entre otras, algunas de las soluciones adoptadas en relación con el tema que nos ocupa. Como puede verse, son por demás heterogéneas. Como heterogéneas son también las fórmulas jurídicas que a tal fin sancionan los textos estatutarios ya citados, que regulan las relaciones de las Comunidades con las correspondientes Diputaciones. En relación con ello, los procedimientos técnicos a través de los que se articula la consideración de las Diputaciones como los órganos periféricos de gestión ordinaria de los servicios de la Comunidad son igualmente variados: mientras en unos casos se asume la fórmula de la delegación, en otros, junto a ella, se sanciona la de la transferencia de funciones por Ley de la Comunidad, posibilidad que en lo sancionado, en que ha sido sancionada lo ha sido con un sinfín de cautelas de carácter eminentemente restrictivo. Y ello, no sólo en los supuestos en los que esa configuración de las Diputaciones como órganos de gestión de los servicios periféricos de la Comunidad aparece como hipótesis a asumir, mera posibilidad, sino también en aquellos otros en los que tal planteamiento se sanciona con carácter imperativo y resulta por ello obligado. Es cierto que, en estos casos, se reconoce que las Diputaciones sean la base de la Administración periférica de las Comunidades Autónomas. No obstante, hay que 
notar la escasa efectividad que en la práctica presentan estos últimos supuestos. En cualquier caso, las Comunidades multiplican su propia organización periférica $y$, en líneas generales, muy frecuentemente, incrementan también sus competencias con las transferencias de funciones y de servicios provinciales.

La valoración cuantitativa de la heterogénea realidad que consideramos obliga a reconocer, por encima de cualquier otra constatación, que se está operando un notable vaciamiento de las competencias de las Diputaciones. Estas, muy señaladamente, a raíz de la Ley reguladora de las Bases de Régimern Local, parece están avocadas a reducir sus competencias provinciales propias, para concentrar sus funciones en aquellas otras, subsidiarias de las de los Ayuntamientos, en relación con lo que se están convirtiendo en generosas y benéficas entidades protectoras; en ocasiones, con la concurrencia en tales tareas de otras Administraciones públicas.

\section{CONSIDERACIONES FINALES}

Señalaba al comienzo que la CE había garantizado la autonomía provincial; en términos análogos, y de modo explícito, la totalidad de los Estatutos. El propio TC ha insistido también en la indisponibilidad por el legislador ordinario del núcleo esencial de las competencias de las Diputaciones. No obstante, el desarrollo legislativo posterior, al no estar precisado ese núcleo competencial indispensable, parece mermar su significado como entidad local con servicios propios, reduciéndola, exclusivamente, a ejercer sus funciones subsidiarias en relación con las competencias municipales. $Y$ ello, como acaba de indicarse, con otras agrupaciones municipales cuya actividad también converge en esa tarea. No creo sea buena la solución, a la que no parece haya sido ajeno ese afán de ocupación de Poder, al que me refería al comienzo; afán, también, iconoclasta respecto de aquellas instituciones que, de una u otra forma, pueden resultar competitivas.

No es buena la solución, digo, comenzando para las propias Comunidades Autónomas. Es fácil convenir que a éstas les resulta más fácil -sobre todo, más cómodo-crear su propia Administración periférica, que no entrar en el juego de unas relaciones, desde luego complejas, con otras entidades regidas además, con frecuencia, por fuerzas políticas diferentes. Esto es cierto. No lo es menos, sin embargo, el extraordinario mayor costo que ello supone; $y$, también, insisto una vez más, el no menos extraordinario deterioro que, en general, sufre la prestación del servicio, que ahora realiza, generalmente, una Administración improvisada y del que se despla- 
zan organizaciones cuya solvencia aparecía por todos reconocida y no cuestionada.

La cuestión, no hay duda, está en ponderar ventajas e inconvenientes; y hacerlo, además, con esa objetividad y ese sentido de servicio a los intereses generales que prescribe el artículo $103 \mathrm{CE}$. Un planteamiento que es obligado asumir también desde la perspectiva que postula la afirmación y consolidación del propio fenómeno regional, en el que sin duda alguna una de las cuestiones más candentes por resolver es la de la ordenada interconexión de las distintas Administraciones territoriales con el fin de obtener de ella los más efectivos rendimientos sociales. Tarea necesaria, en la que en buena parte se juega el futuro efectivo de nuestras Comunidades Autónomas, y no cabe plantear sólo desde las relaciones de estas últimas con el Estado. Requiere hacer entrar en juego también las posibilidades que al respecto cabe derivar de la colaboración con ellas de las distintas Administraciones locales (24).

Las experiencias del derecho comparado tienen sobre este particular un significado por demás relativo. Es lógico. Es el que siempre ofrecen todos los temas de carácter organizativo. En nuestro caso, además, nos encontramos con que las Diputaciones Provinciales, resultado de un muy definido proceso histórico (25) han alcanzado una consistencia y una operatividad que no ofrecen las organizaciones de carácter semejante que podemos encontrar en el derecho comparado. No obstante, y aunque sea muy brevemente, no será ocioso referir la experiencia italiana en los términos que recuerda M. S. Giannini (26): la Constitución -señalatambién ha constitucionalizado la provincia al establecer en su artículo 129, 1, que "el territorio se divide en municipios y provincias», sin perjuicio de prever igualmente en el apartado siguiente una subdivisión provincial, el circondario, que ha resultado sin efectividad real. En Sicilia se suprimió la provincia que fue sustituida por instituciones de carácter consorcial. En las regiones de régimen ordinario, las Leyes de 1977 y la sanitaria de 1978 redujeron las competencias de las provincias. A partir de entonces, la provincia quedaría como organismo casi desprovisto de compe-

(24) Que la articulación entre las distintas Administraciones Públicas constituye actualmente problema básico y fundamental, precisamente para la consolidación de las Comunidades Autónomas, parece está fuera de duda: a ello me he referido, en concreto, en la última parte del Estudio preliminar en S. MARTín-RETORTILLO Pasado, presente y futuro de las Comunidades Autónomas. Madrid, 1989, 49 ss

(25) Es obligado reiterar expresamente aqui la referencia a E. GARCIA DE ENTERRIA, op. cit. supra, nota 2.

(26) Vid., M. GIANNINI La experiencia italiana en la comarca como ente territorial, Barcelona, 1984, 12 ss. 
tencias, generalizándose la formación de agrupaciones municipales (comprensori). No obstante, la experiencia ha acreditado la ineficacia de este nuevo escalón intermedio, circunstancia que ha conducido al refortalecimiento de la provincia, básicamente, como entidad de programación $y$, a largo plazo también, como ente gestor intermedio.

Es aquí, realmente, donde debe centrarse el tema. Reconocimiento o no de intereses a satisfacer en ámbitos territoriales intermedios. En caso afirmativo, la opción a asumir no ofrece duda alguna, al contar ya con entidades consolidadas que, además, han venido desempeñando una labor ampliamente reconocida. La experiencia italiana a la que acabo de referirme puede ser desde luego ilustrativa. Es por ello que hay que augurar que, superada la animadversión a las provincias y pasadas de moda las posibles soluciones comarcales, vuelva a replantearse la necesidad de fortalecer ese escalón organizativo intermedio, que cuenta ya con medios consolidados para hacer frente a las necesidades de gestión de servicios que, siendo de carácter supramunicipal, no deban residenciarse en el escalón regional. El futuro, pues, de las Diputaciones, está, por una parte, en desarrollar su carácter de ente intermedio entre los municipios de la región. Frente al nuevo centralismo de muchas de las de las Comunidades Autónomas, los municipios deben reinvindicar su derecho a gestionar autónomamente los intereses de las comunidades vecinales que aquéllas institucionalizan. $Y$, ante la insuficiencia de muchos municipios, es la provincia -en cuyos órganos de gobierno están representadosla llamada directamente a constituir el ente intermedio gestor de esos servicios supramunicipales; sin intermediación alguna. Además, reconocimiento de servicios propios: nuevas experiencias avalan lo que se señala: así los ensayos recientes en materia de abastecimiento de agua, de diferenciar los servicios de aducción, que corresponderían a las Diputaciones, y los de distribución que continuarían siendo competencias municipales; los planteamientos en materia de ordenación urbanística a nivel provincial; los de las haciendas locales y otros muchos -asistencia a la agricultura, transportes, cultura- son realmente expresivos en relación con lo que se dice. Van por ese camino. Un camino que nada impide -antes exige- que pueda extenderse a otros ámbitos del actuar del sector público. En cualquier caso, plantear el papel a desempeñar por las Diputaciones en los términos que expresamente permite $-y$ que en ocasiones, impone- nuestro ordenamiento constitucional, exige una dosis importante de racionalidad en el juego entre los distintos Poderes públicos, abandonando enunciados estricta-. mente competitivos. $Y$ requiere también, como tuve ocasión de 
señalar hace algunos años (27), una profunda reconsideración por parte de las propias Diputaciones de su organización y de sus modos de actuar que, entiendo, deben abandonar el plácido papel de benéficas distribuidoras de fondos entre los municipios, para actuar, con las dificultades y riesgos que ello comporta, de modo mucho más operativo a como actualmente lo hacen en la prestación directa de no pocos servicios. 